\title{
A CIÊNCIA E A ANGÚSTIA
}

Cláudio Oliveira ${ }^{\star}$

\section{Resumo}

A partir de Heidegger e Lacan abordamos a relação entre a ciência, a angústia e o nada. Flagramos uma abordagem do problema da ciência semelhante em Heidegger e Lacan: para ambos, o desconhecimento da angústia por parte da ciência deve-se a algo que chamamos, conforme Lacan, a foraclusão do nada ou, conforme Heidegger, o não querer saber do nada. Mantendo-se na tradição metafísica, a ciência não acredita que nada possa surgir do nada, isto é, não acredita que o nada possa ter efeitos. Heidegger e Lacan mostram que o nada não só pode ter efeitos, como pode ser causa de muitas coisas, por exemplo, da angústia.

Palavras-chave: Ciência. Angústia. Nada. Heidegger. Lacan.

\section{SCIENCE AND ANGUISH}

\begin{abstract}
Based on Heidegger and Lacan, we think the relation between science, anguish and nothing. We find a similar approach of the problem of science in Heidegger and Lacan: in both authors, the science's unfamiliarity with the anguish has to do with something we call, using a term of Lacan, the forclusion of the nothing or, using the expression of Heidegger, not to want to know of the nothing. Remaining itself in the Metaphysical tradition, science does not believe that the nothing can have effects. However, what Heidegger and Lacan show are that the nothing not only can have effects, but also be cause of many things, as, for example, the anguish.
\end{abstract}

Keywords: Science. Anguish. Nothing. Heidegger. Lacan.

^ Doutor em filosofia pela Universidade Federal do Rio de Janeiro (UFRJ) e professor do Departamento de Filosofia da Universidade Federal Fluminense (UFF), onde participa também do corpo docente do Curso de Especialização em Psicanálise e Laço Social e coordena o Laboratório de Psicanálise e Laço Social (LAPSO). É um dos organizadores do livro Clínica Psicanalítica das Psicoses (Niterói: EdUFF, 2005) e um dos autores de 10xFreud (Rio de Janeiro: Ed. Azougue, 2005)

Endereço: Rua Ministro João Alberto, 100/109 - Jardim Botânico - Rio de Janeiro - RJ - CEP: 22.461-260.

E-mail: claudio.oliveira@uol.com.br 
Um ano após Freud lançar Inibição, sintoma e angústia, em 1926, Heidegger publica, em 1927, Ser e tempo, a obra em que sustenta a tese, comum à psicanálise de Freud, de uma especificidade da angústia, ante os outros afetos, expressa na máxima de que a angústia é o afeto fundamental. Dois anos mais tarde, mais precisamente no dia 24 de julho de 1929, Heidegger realiza sua aula inaugural pública na Universidade de Freiburg. Diante de todo o corpo docente e discente da universidade, como era de praxe então, ele assumia a cátedra de filosofia ocupada anteriormente por Edmund Husserl. Essa aula inaugural, a que Heidegger deu o título $O$ que é Metafísica?, foi publicada no mesmo ano, gerando uma enorme repercussão e, segundo Heidegger, um número ainda maior de malentendidos. A conferência tratava da relação entre a angústia e o nada, e isso foi o suficiente para se ver nela um elogio do niilismo, da depressão, da covardia e do irracionalismo, além de uma negação da lógica.

Mas por que Heidegger escolhe o tema da angústia para se apresentar como professor titular à universidade na qual não só fez toda a sua formação como estudante, mas também onde iria realizar toda a sua carreira como professor? Em outras palavras: por que ele decide falar sobre a angústia para a universidade? O que a angústia tem a ver com a universidade? A resposta que Heidegger dá a essa pergunta, em sua conferência, pode parecer, à primeira vista, bastante paradoxal. Ele acha que a angústia tem a ver com a universidade por causa da ciência.

Ao se propor colocar essa questão diante daquele público universitário, Heidegger lembra que uma interrogação só é uma interrogação quando aquele que interroga está implicado na interrogação, isto é, é problematizado por ela. Nesse sentido, a interrogação que ele pretende expor para aqueles que o escutam naquela aula inaugural deve questionar, em suas palavras, "a situação fundamental da existência daquele que interroga". Ora, "a nossa existência", diz ele, "Na comunidade de pesquisadores, professores e estudantes - é determinada pela ciência. O que acontece de essencial nas raízes de nossa existência na medida em que a ciência se tornou nossa paixão?" (HEIDEGGER, 1979, p. 35). Com essa pergunta, Heidegger pretende justificar que se fale, nessa aula inaugural, da universidade a partir de uma reflexão sobre a ciência. Mas por que falar também da angústia? O que a ciência tem a ver com a angústia?

Aparentemente, a resposta deveria ser: nada. Mas Heidegger dá a essa resposta um outro sentido. Para ele, o que liga, invisivelmente, a ciência e a angústia é o nada. Mas a ligação que o nada cria entre a ciência e a angústia é, ela mesma, bastante peculiar. Porque a angústia e a ciência não estão ligadas ao nada da mesma forma, muito pelo contrário. $\mathrm{O}$ nada, enquanto aquilo de que se trata na experiência da angústia - é esta a tese que Heidegger quer defender nesta aula inaugural -, é precisamente aquilo que deve ser rejeitado pela ciência, à medida que esta se constitui por uma referência, não ao nada, mas ao mundo, e por uma referência ao mundo em que o nada não tem lugar. Nessa referência ao mundo que lhe é própria, desinteressada do nada, "a ciência procura o ente, para [...] transformá-lo em objeto de investigação" (HEIDEGGER, 1979, p. 36). A ciência é, nesse senti- 
do, não só uma maneira muito objetiva de questionar, determinar e fundar o ente, mas, ao mesmo tempo, uma referência ao mundo que define um modo da existência, a existência científica. O que Heidegger procura, com essa reflexão, é o enraizamento da ciência em seu fundamento essencial, uma vez que, na existência científica, a única coisa que ainda confere uma unidade à ciência parece ser a organização técnica das universidades e faculdades. Seu esforço é buscar, na referência ao mundo que constitui a existência científica, algo que unifique o campo científico, mas não a partir de uma referência meramente técnica, metodológica ou burocrática. $\mathrm{O}$ que permite unificar as ciências, segundo Heidegger, embora isso pareça num primeiro momento bastante paradoxal, é algo que, em sua fundação, elas rejeitam: o nada. A referência ao mundo que impera em todas as ciências, que faz com que a ciência procure o ente para objetivá-lo, essa referência ao mundo muito particular que é a da ciência, Heidegger a descreve de um modo também muito particular, ao trazer o nada para a questão. Apropriando-se daquilo que os próprios cientistas teriam a dizer em defesa da ciência - uma defesa em que, no entanto, a própria ciência se desnuda -, Heidegger falará da referência ao mundo científico e do comportamento científico, nestes termos:

Aquilo para onde se dirige a referência ao mundo [da ciência] é o próprio ente - e mais nada.

Aquilo de onde todo o comportamento [científico] recebe sua orientação é o próprio ente - e mais nada (HEIDEGGER, 1979 , p. 36).

Heidegger, ao se deter nessas afirmações que ele atribui ao cientista, chama a atenção para a presença nelas de algo com que, em psicanálise, nos familiarizamos em chamar de denegação. Há algo denegado nessas afirmações e esse denegado é o nada:

Mas o digno de nota é que, precisamente no modo como o cientista se assegura o que lhe é mais próprio, ele fala de um outro. Pesquisado deve ser o ente e mais - nada; somente o ente e além dele - nada; unicamente o ente e além disso nada.

Que acontece com este nada? É por acaso que espontaneamente falamos assim? É apenas um modo de falar - e mais nada?

Mas por que nos preocupamos com este nada? (HEIDEGGER, 1979, p. 36).

Heidegger mostra-nos, ao assim operar sobre a fala do cientista, que ao assegurar-se do que lhe é mais próprio, o cientista fala de um outro. Mesmo que o rejeitando ou abandonando-o como um elemento nadificante, o cientista, de algum modo, o admite. Precisamente porque nada admite.

O cientista certamente acusará que se trata aí de um mero jogo de palavras. Para defender-se desse jogo de palavras, o cientista evita a denegação e afirma 
peremptoriamente: ele se ocupa unicamente do ente, unicamente daquilo que é. O que não é, o nada, não lhe interessa. Esta atitude do cientista trai, no entanto, algo que Heidegger não hesita em descrever como horror ao nada: "O nada - que outra coisa pode ser para a ciência senão horror e fantasmagoria?" (HEIDEGGER, 1979, p. 36). Daí ele formular a relação da ciência com o nada, de um modo ainda mais radical do que aquele que ele atribui ao cientista e que podemos considerar, $a$ posteriori, bem lacaniano: "a ciência nada quer saber do nada" (HEIDEGGER, 1979, p. 36). É uma fórmula bem próxima disso que Lacan chamou de "foraclusão", para traduzir o termo alemão Verwerfung, que ele isolou, no texto de Freud, para pensar a psicose. Em "A ciência e a verdade", um escrito de 1966, Lacan afirma que as relações da Verwerfung com a psicose apenas aparentemente se opõem à tentativa de demarcação estrutural da ciência a partir dessa noção (LACAN, 1998, p. 889). O não querer-saber-nada, como aquilo em que a ciência se sustentaria, é a formulação em que reconhecemos, segundo Lacan, a Verwerfung ou foraclusão.

Nessa rigorosa rejeição científica do nada, Heidegger aponta, no entanto, para a denegação que constitui a posição do cientista, pois, como ele mesmo diz, "dele sabemos, enquanto dele, do nada, nada queremos saber". Ao não querersaber-nada do nada, à Verwerfung da Ciência descrita por Heidegger, corresponderia a Verneinung do cientista. A denegação e a foraclusão são, nesse sentido, o modo como o cientista e a ciência sabem do nada. $O$ nada floracluído pela ciência retorna denegado pelo cientista. Heidegger assim conclui sua colocação a respeito do problema:

A ciência não quer saber do nada. Mas não é menos certo também que, justamente ali onde ela procura expressar sua própria essência [através do cientista], ela recorre ao nada. Aquilo que ela rejeita, ela leva em consideração. Que essência ambivalente se revela aí? (HEIDEGGER, 1979, p. 36).

Essa ambivalência - um termo tão conhecido dos psicanalistas - só se explica por uma referência indireta à angústia que atravessa de um modo invisível a relação do cientista com o nada, por mais que, por estrutura, essa relação esteja foracluída do discurso científico. A denegação, que encontramos na fala do cientista, opera como o modo de saber do nada que impede que, no cientista, tenha lugar um outro modo de saber do nada: a angústia.

Mas o nada rejeitado e denegado acaba vindo à tona. Em geral, como efeitos do discurso científico sobre aqueles que sequer fazem ciência. Outras vezes, na figura do próprio cientista, que experimenta em si mesmo essa aproximação do nada. Nesse instante particular, o cientista experimenta a angústia. Lacan se refere a esse momento, em uma ocasião, em 1974, numa entrevista concedida a jornalistas italianos e que foi publicada recentemente por Jacques Alain-Miller sob o título $O$ Triunfo da Religião. Curiosamente, perto do fim dessa entrevista, Lacan, ao ser perguntado sobre a filosofia, se refere a Heidegger. Ele diz que há coisas a partir das quais a filosofia ainda teria algo a dizer, mas que, depois de Heidegger que, segundo ele, teria dito duas a três coisas sensatas -, "já faz muito tempo que 
a filosofia não diz absolutamente nada inteligente para o mundo"(LACAN, 2005, p. 99).

Lacan parte, nessa entrevista, da afirmação freudiana de que há um certo número de posições insustentáveis, a de governar, a de educar e a de analisar. Mas Lacan acrescenta à lista de Freud a posição do cientista [savant] como uma posição igualmente insustentável, o que não teria sido apontado por Freud, a seu ver, por ser o tema da ciência, para Freud, um tabu (LACAN, 2005, p. 73). Lacan chega a dizer, de um modo bastante irônico, que provavelmente por causa de Freud "ninguém sequer pensou em dizer que é tão impossível haver uma ciência que tenha resultados quanto governar e educar" (LACAN, 2005, p. 73). Como Freud não falou disso, ninguém sequer pensou que poderia dizê-lo. Mas Lacan acredita que seja somente pela psicanálise que se possa ter uma pequena desconfiança disso.

Esse impossível, esse insustentável, que para Lacan constitui a posição dos que governam, educam, analisam e fazem ciência, é o que estabelece entre eles uma relação com a angústia. Mas apesar de assumirem uma posição insustentável, os que fazem ciência e educam, segundo Lacan, não se dão conta disso.

Os que educam, por exemplo, embora estejam autorizados a fazê-lo por uma espécie de tampão que os apazigua, e que chamamos de diploma, não têm, nem por isso, sequer "a menor idéia do que é educar". As pessoas, afirma Lacan, "não se apercebem muito bem do que elas querem fazer quando educam [...], elas refletem sobre isso raramente" (LACAN, 2005, p. 70). Segundo ele, quando elas pensam no que é educar, "apodera-se delas a angústia" (LACAN, 2005, p. 70). O sinal de que há algo de insustentável em suas posições é o fato de que elas são tomadas algumas vezes por esse algo de muito particular e que "somente os analistas conhecem verdadeiramente bem: a saber, a angústia" (LACAN, 2005, p. 70). Contra a angústia, os que educam procuram remédio no que Lacan chama de "concepções do homem" (LACAN, 2005, p. 71). Acho que basta ter um pouquinho de contato com qualquer pedagogo para saber do que Lacan está falando. De qualquer modo, poderíamos pensar no que seria um educar que sustentasse sua posição como impossível. O ensino da psicanálise, fora ou dentro da universidade, talvez seja uma oportunidade para colocarmos essa questão.

Quanto à ciência, embora seja igualmente uma posição impossível, é óbvio que os cientistas não têm a menor idéia disso, o que, segundo Lacan, é a sorte deles, pois quando algo disso aparece, também eles começam a ter crises de angústia:

Suas crises de angústia não têm mais importância do que qualquer crise de angústia. A angústia é uma coisa totalmente fútil, medrosa [foire]. Mas é divertido que se tenha visto nos últimos tempos alguns dentre os cientistas [savants] que trabalham em laboratórios totalmente sérios se alarmarem de repente, terem medo [avoir les foies], o que significa, em francês, ter cagaço [avoir la troille], e dizerem: "Todas essas pequenas bactérias com as quais nós fazemos coisas tão 
maravilhosas, suponham que um dia, depois que nós tivermos feito disso um instrumento verdadeiramente sublime de destruição da vida, um sujeito as tirar do laboratório" (LACAN, 2005, p. 74).

A resposta dos cientistas à angústia foi uma resposta diferente da dos educadores, mas bem conhecida pela psicanálise, pois é uma resposta muito antiga: a interdição. Foram embargadas determinadas pesquisas. O que prova, aos olhos de Lacan, que nem mesmo os cientistas são ainda capazes de tudo. Como eles tiveram uma crise de angústia típica, "um tipo de interdição, ao menos provisória, foi lançada" (LACAN, 2005, p. 75). Dessa situação, Lacan extrai a lição de que a ciência é signo de que o homem é capaz de algo que dá, no entanto, um pouco de angústia, mas como a ciência não tem "a menor idéia do que ela faz, salvo ter um pouquinho de angústia, ela vai continuar um certo tempo" (LACAN, 2005, p. 75-76).

Entretanto, ainda mais impossível que as outras posições é a análise. Não só porque ela é a mais nova dentre as posições impossíveis - o que, de qualquer modo, contribui, já que governar e educar sempre existiram, e fazer ciência, há pelo menos três séculos, enquanto analisar é algo que se faz há pouco mais de cem anos: "a novidade reforça o caráter impossível da coisa", lembra Lacan. A ausência de uma tradição mais longa não torna particularmente mais cômodo, para a maior parte dos analistas, sustentar essa posição (LACAN, 2005, p. 72). Mas o que a torna efetivamente mais impossível que as outras posições, para Lacan, não é isso, e sim o fato de que "ela se ocupa muito especialmente do que não anda" (LACAN, 2005, p. 76), isso que ele considera ter sido o único a tê-lo chamado com este nome: "o real". Por se ocuparem "do que não anda", por só se ocuparem disso, os analistas são forçados a suportá-lo, mas para isso é preciso "que eles estejam vastamente blindados contra a angústia". Só que, diferentemente das outras posições impossíveis, é preciso que os analistas o façam de tal modo que eles possam ao menos falar da angústia, sem denegá-la, rejeitá-la ou recalcá-la. A resposta à angústia dada pelo analista, o que o blinda contra ela - mas sobre isso não falarei aqui - é o desejo do analista.

Mas quanto a poder falar da angústia, mesmo para o psicanalista, isso não é fácil e também não é sem efeito. Quando falou disso, em seu seminário, entre 1962 e 1963, lembra Lacan, isso não deixou de produzir um certo turbilhão e até mesmo, no campo institucional, o que ficou conhecido como a segunda cisão na psicanálise francesa. O seminário sobre a angústia custou a Lacan sua expulsão da IPA e a necessidade de fundar uma nova instituição psicanalítica, a Escola Freudiana de Paris. Falar sobre a angústia não é sem conseqüências. E podemos medir, também por aí, a posição de Heidegger ao falar, em sua aula inaugural, sobre a angústia, supondo que ele soubesse o que estava fazendo, como o suponho aqui.

O que faz com que o analista tenha uma outra relação com a angústia é o fato de ter de se ocupar daquilo de que as outras posições, apesar de igualmente impossíveis, se negam a tratar: do real. O real, enquanto o que não anda, a psicanálise o entende por meio de um termo que ela elevou a uma função essencial: o 
sintoma. Para Lacan - porque o sintoma é "o que não anda" (LACAN, 2005, p. 87) por excelência - ele é "o que há de mais real” (LACAN, 2005, p. 81). Mas o sintoma não é o verdadeiro real ou, como diz Lacan nessa entrevista, "o real real" (LACAN, 2005, p. 82). Lacan faz aqui uma distinção entre o real do sintoma, de que trata a psicanálise, e o verdadeiro real, de que trata a ciência, pois a este real, o verdadeiro, nós só podemos “aceder, segundo ele, por uma via totalmente precisa, que é a via científica. É a via das pequenas equações” (LACAN, 2005, p. 93). Mas este real nos falta completamente. Nós não o temos, dele estamos totalmente separados e isso exatamente pelo fato de, por falarmos, sermos sexuados ou, se quisermos nos utilizar d'alíngua de São João, pelo fato de o verbo ter-se encarnado, pois, como diz Lacan, "é quando o Verbo se encarna que isso começa a andar muito mal" (LACAN, 2005, p. 90).

Partindo d'alíngua de São João, poderíamos dizer que a ciência opera com o significante sem que este encarne, ou sem que a ciência queira saber se ele encarna. O não querer saber do sintoma, na ciência, corresponde, assim, a um não querer saber sobre o ser sexuado, sobre o verbo na carne, porque "sobre esse ponto não há nenhuma chance de que isso tenha jamais sucesso, isto é, que nós tenhamos disso a fórmula, uma coisa que se escreva cientificamente" (LACAN, 2005, p. 94). E é precisamente a partir desse impossível de se escrever que os sintomas proliferam.

Ora, é disso que se ocupam os analistas, "de modo que, contrariamente ao que se crê, eles estão muito mais afrontados com o real que os próprios cientistas" (LACAN, 2005, p. 76). Sobretudo, eles estão afrontados com um real que, desconhecido da ciência, nem por isso deixa de se estender cada vez mais e, paradoxalmente, a partir do exercício da própria ciência. A ciência, como algo novo, não deixa de introduzir, segundo Lacan, "um monte de coisas perturbadoras na vida de cada um" (LACAN, 2005, p. 79). São perturbações que a ciência introduz, tornando as coisas menos naturais, gerando as experiências as mais curiosas, diante das quais "os próprios cientistas começam a ter um pouquinho de angústia" (LACAN, 2005, p. 80). A psicanálise, nesse sentido, está relacionada a essa perturbação que o discurso científico introduz, pois ela não surgiu em um momento histórico qualquer: "ela surgiu correlatamente a um passo capital, a um certo avanço do discurso da ciência" (LACAN, 2005, p. 81). A própria psicanálise faz nitidamente parte desse mal-estar da civilização que Freud descreveu, ela é, desse momento, ela mesma, o sintoma, lembrando apenas que, para Lacan, "o sintoma é o que há de mais real" (LACAN, 2005).

Em seu seminário 10, A Angústia, Lacan nos mostrou que a angústia é signo desse real irredutível ao significante (LACAN, 2004, p. 188), desse real que se apresenta na experiência e que escapa à ciência. Mas talvez o lugar da obra de Lacan que nos permita falar da angústia de modo que possamos retornar a Heidegger sejam esses dois capítulos do seminário 7, A Ética da Psicanálise: "Da criação ex nihilo" e "Pequenos comentários à Margem". Não só porque, no primeiro deles, Lacan fala pela primeira vez do real como nada, servindo-se, para isso, precisamente de Heidegger, mas também porque, no segundo, ele encontra ocasião, mais 
uma vez, para falar da relação da ciência com o real, em termos muito próximos do que Heidegger afirma em $O$ que é metafísica?.

O real que, no seminário A Angústia, Lacan (2004) define como "irredutível ao significante" é o mesmo que ele define, no seminário A Ética da Psicanálise, como "o que padece do significante" (LACAN, 1991). Em ambos os casos, tratase do real que a ciência desconhece, pois a ciência pensa o real como redutível ao significante e, por isso mesmo, em última instância, não há para a ciência nenhum real que padeça do significante. Como se a introdução do significante no real fosse, para a ciência, uma operação que não deixasse restos, como se a introdução do verbo na carne fosse totalmente bem-sucedida que não houvesse padecimento. Mas porque há um real irredutível ao significante, e a angústia é o único sinal seguro disso, por isso mesmo, há um real que padece do significante - o que é uma outra maneira de dizer isso que, na entrevista de 1974, Lacan (2005) chama de "o verbo encarnado", isto é, o corpo sexuado pelo significante ou, melhor dizendo, precariamente sexuado pelo significante, uma vez que não há nenhuma chance de que isso seja bem-sucedido algum dia.

O real que padece do significante, Lacan (1991) dá um nome para isso no seminário A Ética da Psicanálise, ele o chama de "A Coisa", traduzindo a expressão alemã Das Ding, uma expressão que ele vai buscar no Projeto de Freud, mas também num artigo de Heidegger que tem esse título: "Vocês podem, diz ele, facilmente, todos vocês indistintamente, reportar-se à coletânea Ensaios e conferências e ao artigo sobre A Coisa" (LACAN, 1991, p. 151).

Lacan nos lembra que, ao falar sobre "A Coisa", neste artigo, é em torno de um vaso que Heidegger desenvolve sua dialética. Heidegger mostra que, contrariamente a uma tradição que surge com Aristóteles, e avança até o discurso científico, o vaso não se cria a partir da matéria, mas em torno de um vazio. Eé aqui que podemos aproximar o que Lacan chama de real e o que Heidegger, em $O$ que é Metafísica?, chama de "nada":

Ora, se vocês considerarem o vaso, na perspectiva que inicialmente promovi, como um objeto feito para representar a existência do vazio no centro do real que se chama a Coisa, esse vazio, tal como ele se apresenta na representação, apresenta-se, efetivamente, como um nihil, como nada (LACAN, 1991, p. 153).

A modelagem desse significante que é o vaso permite a Lacan estabelecer "uma identidade entre a modelagem do significante e a introdução no real de uma hiância, de um furo" (LACAN, 1991, p. 153). A introdução dessa hiância no real pelo significante é também a constituição do real que padece do significante. Em outras palavras: a introdução do furo no real pelo significante é a constituição da própria Coisa, enquanto, para Lacan, ela define o humano, "embora, justamente, o humano nos escape" (LACAN, 1991, p. 157). O exemplo esquemático do vaso permite a Lacan apreender a Coisa "na relação que situa o homem como o medium entre o real e o significante" (LACAN, 1991, p. 162). Entre o real e o significante está o real irredutível ao significante, o real que padece do significante, o real do 
que não anda, o real do sintoma: o homem. Esse real, esse nada que Lacan chama de a Coisa, será sempre representado por um vazio, precisamente pelo fato de a Coisa "não poder ser representada por outra coisa - ou, mais exatamente, de ela não poder ser representada senão por outra coisa" (LACAN, 2005, p. 162).

$\mathrm{O}$ vaso de Heidegger explicita, por outro lado, o fato de que toda criação, e não apenas a divina, é sempre uma criação ex nihilo, isto é, uma criação do nada, a partir do nada, em torno do nada. O vaso, nesse sentido, contradiz algo a que Heidegger se refere na conferência $O$ que é metafísica? e que Lacan retoma, neste capítulo que foi intitulado por isso mesmo "Da criação ex nihilo": o fato de que "sobre o nada, a metafísica se expressa desde a Antigüidade numa enunciação,sem dúvida, de forma multívoca: ex nihilo nihil fit, do nada nada vem" (HEIDEGGER, 1979, p. 43). Lacan retoma essa afirmativa de Heidegger assim: "Nada é feito a partir de nada. Toda a filosofia antiga se articula em torno disso. Se nos é difícil pensar a filosofia aristotélica, é porque ela deve ser pensada segundo um modo que jamais omite que a matéria é eterna e que nada é feito de nada" (LACAN, 1991, p. 153). Em sua conferência, Heidegger aponta para o fato de que a tradição cristã nega esse enunciado, ao afirmar que ex nihilo, do nada, Deus criou todas as coisas. É verdade que essa tradição, lembra Heidegger, nem mesmo se preocupa em pensar que, "se Deus cria do nada, justamente precisa poder entrar em relação com o nada" (HEIDEGGER, 1979, p. 43). Mas para Lacan, pouco importa se pensamos ou não sobre a relação de Deus com o nada. Como ele mesmo diz, "o que quer que façam, e mesmo que vocês estejam se lixando para o Criador como para a morte da bezerra, o fato é que é em termos criacionistas que vocês pensam" (LACAN, 1991, p. 157).

O que está em jogo nessa discussão - que pode parecer excessivamente metafísica, mas à qual tanto Lacan quanto Heidegger dão um valor essencial - é o fato de que, mantendo-se nessa tradição metafísica, a ciência não acredita que nada possa surgir do nada, ou, em outras palavras, não acredita que o nada possa ter efeitos. Ora, o que Heidegger e Lacan mostram é que o nada não só pode ter efeitos, como ser causa de muitas coisas, como a angústia, o sintoma e a inibição. Isso sem falar nos vasos.

\section{REFERÊNCIAS}

FREUD, S. Inibição, sintoma e angústia (1926). In: Obras psicológicas completas. Rio de Janeiro: Imago, 1977. v. XX. E. S. B.

HEIDEGGER, M. O que é Metafísica? In: Conferências e escritos filosóficos. Tradução, introdução e notas de Ernildo Stein. São Paulo: Abril Cultural, 1979. (Os Pensadores).

. Ser e tempo. Petrópolis: Vozes, 1997.

LACAN, J. A Ciência e a Verdade (1966). In: . Escritos. Tradução Vera Ribeiro. Rio de Janeiro: J. Zahar, 1998. 
LACAN, J. A. O seminário: a ética da psicanálise. Tradução Antonio Quinet. Rio de Janeiro: J. Zahar, 1991. Livro 7. Texto estabelecido por Jacques-Alain Miller. . Le séminaire: l'angoisse. Paris: Seuil, 2004. Livre X. Texte établit par Jacques-Alain Miller.

Le triomphe de la religion (1974). Paris: Seuil, 2005. Texte établit par Jacques-Alain Miller.

Recebido em: janeiro/2006 Aceito em: março/2006 